\title{
Constitutive phosphorylation of Janus kinase 2 in the GL15 glioblastoma derived human cell line
}

\author{
MIRIAM SCIACCALUGA ${ }^{1,2}$, GIAN LUIGI GIANFRANCESCHI ${ }^{1,2}$, SIMONE ROCCO ${ }^{1}$, GIOVANNI GERMANO ${ }^{1}$, \\ GIOVANNI ROTI ${ }^{3}$, PAOLO GORELLO ${ }^{3}$, ROBERTA LA STARZA ${ }^{3}$ and EMILIA CASTIGLI ${ }^{1,2}$ \\ ${ }^{1}$ Department of Cellular and Environmental Biology, Section of Cellular and Molecular Biology; \\ ${ }^{2}$ CEMIN (Centro di Eccellenza 'Materiali Innovativi Nanostrutturati'); ${ }^{3}$ Hematology and \\ Bone Marrow Transplantation Unit, University of Perugia, 06100 Perugia, Italy
}

Received July 3, 2006; Accepted August 28, 2006

\begin{abstract}
The notion that gliomas could originate from mutated glial precursor cells highlights the possibility of modulating the proliferative and migratory behaviour of glioma cells by acting on the molecular mechanisms operative during the development of the Central Nervous System (CNS), but absent in the normal adult brain. We show that the GL15 glioblastoma derived human cell line displays a high expression of nestin which, combined with the previously demonstrated high expression of vimentin, constitutes a characteristic of astrocyte restricted precursors. We also show that, in analogy with some leukaemia cells, GL15 cells display the constitutively phosphorylated form of Janus kinase 2 (JAK2), a tyrosine kinase expressed during CNS development but undetectable in the normal adult brain. The constitutive activation of JAK2 does not result from chromosomal aberrations involving the JAK2 gene, but most probably from abnormally activated transduction systems operative in glioblastoma cells. We then investigated the effects of tyrphostin AG490, an inhibitor of JAK2 autophosphorylation, on GL15 cell growth. In the absence of exogenous growth factors and cytokines, $10 \mu \mathrm{M}$ tyrphostin AG490 induces an S phase arrest, combined with a partial impairment of the G2 phase of the cell cycle. The abnormally activated JAK2 could then potentially represent a target for a selective pharmacological approach in glioblastoma cells in which a combination of glial precursor characteristics and genetic alterations occurs.
\end{abstract}

\section{Introduction}

The idea that brain tumors could originate from embryonic or adult precursor cells is the object of intensive investigation

Correspondence to: Dr E. Castigli, Department of Cellular and Environmental Biology, Section of Cellular and Molecular Biology, University of Perugia, via Pascoli, 06123 Perugia, Italy

E-mail: castigli@unipg.it

Key words: glioblastoma, Janus kinase 2, tyrphostin AG490
$(1,2)$. The concept that gliomas could originate from mutated glial precursor cells highlights the possibility of modulating the proliferative and migratory behaviour of glioma cells by acting on the molecular mechanisms operative during Central Nervous System (CNS) development but absent in the normal adult brain. Some of these mechanisms have been identified in human gliomas. Therefore the use of specific inhibitors of the key factors controlling these mechanisms could constitute a possible experimental approach in the study of gliomas. A possible candidate is the Janus Kinase 2 (JAK2) protein tyrosine kinase involved in the downstream effects of some growth factor and cytokine receptor activation (3). In fact the expression of JAK2 is evident during CNS development $(4,5)$ but is undetectable in the normal adult brain (6). The activity of JAK2 in the normal adult brain seems to be related to pathological states in which inflammatory cytokines are involved (7-10).

In our study we investigate the presence of the active form of JAK2 and the genetic abnormalities involving the JAK2 gene. Moreover we evaluate the effects of tyrphostin AG490, the inhibitor of JAK2 activity (11), on the GL15 (12-15) glioblastoma derived human cell line. The analysis of this glioblastoma derived cell line behaviour, after treatment with AG490, could be considered a specific response of immature glial populations. In fact GL15 cells constitutively express vimentin (12), and in this report we show the constitutive expression of nestin. The expression of both vimentin and nestin, embryonic intermediate filament proteins, has been considered a characteristic of astrocytic precursors (16).

Tyrphostin AG490 has been successfully used in a mouse model to selectively inhibit acute lymphoblastic leukaemia cell growth in vitro and in vivo and it has been demonstrated that this effect was due to the inhibition of JAK2 (11). Further studies have also shown that the inhibitory effects on cell growth by AG490 were selective for human leukaemia cells in which chromosomal aberrations lead to the constitutive activation of JAK2 $(17,18)$. In these studies AG490 was shown to be able to potently inhibit the proliferation of leukaemia cells at a concentration that has few inhibitory effects on normal hematopoiesis.

Our results show that the specific response of the subpopulations of glioblastoma cells to AG490 is due to the 
presence of molecular mechanisms, operative during glial cell development but absent in adult glia, combined with the altered controls of cell cycle progression typical of glioblastoma.

\section{Materials and methods}

Cell cultures. Cultures of the GL15 glioblastoma multiforme cell line were grown in minimum essential medium (MEM) supplemented with $10 \%$ heat-inactivated foetal bovine serum (FBS), $100 \mathrm{IU} / \mathrm{ml}$ penicillin $\mathrm{G}, 100 \mu \mathrm{g} / \mathrm{ml}$ streptomycin, $2 \mathrm{mM}$ glutamine and $1 \mathrm{mM}$ sodium pyruvate. The flasks were incubated at $37^{\circ} \mathrm{C}$ in a $5 \% \mathrm{CO}_{2}$ humidified atmosphere. The medium was changed twice weekly and the cells were subcultivated when confluent.

After one day of subculturing the GL15 cells were treated with $10 \mu \mathrm{M}$ tyrphostin AG490 (Calbiochem) in serum-free medium, and analysed 3 days after treatment. In all the experiments the final concentration of dimethyl sulphoxide (DMSO) was $0.1 \%$. The controls containing the same amount of DMSO were included at each experimental time point. Morphological analysis of the cells was performed with a contrast phase Nikon microscope. Cell count was performed after trypsinization using a Burker camera.

Indirect immunofluorescence. The cells were extensively washed with phosphate-buffered saline (PBS), immersed in cold methanol, kept at $-20^{\circ} \mathrm{C}$ for $7 \mathrm{~min}$ and dried in air. The cells were then incubated for $60 \mathrm{~min}$ at room temperature with a rabbit anti-GFAP (Dakopatts, Denmark) polyclonal antibody (diluted 1:300 in PBS containing $0.3 \%$ bovine serum albumin) and washed in PBS. After treatment with tetramethylrhodamin isothiocyanate (TRITC, Sigma) conjugated goat antirabbit IgG (diluted 1:200 in PBS containing 0.3\% albumin) and washing $3 \mathrm{x}$ with PBS containing $0.1 \%$ Tween-20 and twice with PBS, the preparations were incubated with $2 \mu \mathrm{g} / \mathrm{ml}$ DAPI (4,6-diamidino-2-phenylindole) (Sigma) for $5 \mathrm{~min}$ and dried in air. The same procedure was used with a mouse antiB-tubulin antibody (Sigma), diluted 1:50 in PBS containing $0.3 \%$ bovine serum albumin and the anti-mouse $\mathrm{IgG}$ (Fab specific), fluorescein isothiocyanate (FITC, Sigma) conjugated antibody (diluted 1:100), except for a permeabilization step performed by treatment with PBS containing $0.1 \%$ Triton $\mathrm{X}-100$ for $5 \mathrm{~min}$. The preparations were observed with a DMRB Leica microscope.

ELISA detection of cytoplasmic nucleosomes. Determination of the cytoplasmic histone-associated-DNA-fragments was performed using the Cell Death Detection ELISA (Plus) kit (Roche), following the instructions of the manufacturer. The results are expressed as a percentage of the optical density, resulting from the activity of the peroxidase-conjugated antiDNA-antibody complexed with cytoplasmic nucleosomes of treated cells, compared to the control.

SDS-polyacrylamide gel electrophoresis and immunoblotting. GL15 cell cultures were washed with PBS and scraped with $62.5 \mathrm{mM}$ Tris- $\mathrm{HCl}$ (pH 6.8), 2 mM EDTA, $0.5 \%$ Triton $\mathrm{X}-100$, protease inhibitor cocktail (Sigma), and $0.1 \%$ SDS. The protein content was determined by the Bio-Rad protein assay kit.
The proteins were separated by SDS-PAGE in acrylamide gels using the method described by Laemmli (19), then transferred to nitrocellulose filters according to Towbin et al (20). The immunolabeling of nestin, GFAP and vimentin was performed as described by Tognon et al (21). The primary antibodies were: A rabbit anti-nestin polyclonal antibody (Chemicon), a rabbit anti-GFAP policlonal antibody (Dakopatts) and a mouse anti-vimentin monoclonal antibody (Roche).

When analysing the phosphorylated form of JAK2 by the rabbit phospho-JAK2 (Tyr1007/1008) antibody (Cell Signaling Technologies), the phosphatase inhibitor cocktail II (Sigma) was added to the extraction buffer. The analysis of the actin content performed by using the mouse anti-actin monoclonal antibody (ICN Biomedicals) was used as the control.

The secondary antibodies were the peroxidase-conjugated goat anti-rabbit immunoglobulins (Pierce) and the peroxidaseconjugated goat anti-mouse immunoglobulins (Pierce).

The Enhanced Chemiluminescence detection was performed by using the instructions of ECL ${ }^{\mathrm{TM}}$ Western blotting (Cell Signaling Technologies).

Measurements of cell cycle by flow cytometry. Following the different treatments, aliquots of the cell suspension were transferred into centrifuge tubes and washed once with PBS (400 x g, $7 \mathrm{~min}$ ), then successively processed for cell cycle analysis by propidium iodide (PI) staining and flow cytometry. Briefly, the cell pellet was resuspended in $0.5 \mathrm{ml}$ hypotonic fluorochrome solution $(50 \mu \mathrm{g} / \mathrm{ml} \mathrm{PI}$ in $0.1 \%$ sodium citrate plus $0.1 \%$ Triton $\mathrm{X}-100)$ in $12 \times 75 \mathrm{~mm}$ polypropylene tubes (Becton-Dickinson, Lincoln Park, NJ, USA). The tubes were kept at $4^{\circ} \mathrm{C}$ for at least $30 \mathrm{~min}$ before flow cytometric analysis. The PI fluorescence of the individual nuclei was measured using a FACScan flow cytometer (Becton-Dickinson, Mountain View, CA, USA) at a wavelength of $488 \mathrm{~nm}$. The percentages of the cells in the G0/G1, $\mathrm{S}$ and $\mathrm{G} 2 / \mathrm{M}$ phases were calculated using CellFIT cell-cycle analysis version 2.0.2. software.

Fluorescence in situ hybridization (FISH). Metaphase FISH was performed with the DNA clone RP1-134N20 for JAK2/ 9p24 as previously described (22). The PAC clone belongs to the Roswell Park Cancer Institute library RP1, http:// Www.chori.org/BACPAC, and was kindly provided by Professor P. Marynen, University of Leuven, Belgium). Five cells were analysed with a fluorescence microscope (Provis, Olympus, Milan, Italy) equipped with a CCD camera (Sensys, Photometrics) run by SmartCapture software (Vysis, Stuttgart, Germany).

dHPLC. Genomic DNA from GL15 cell lines, and genomic DNA from blood of a patient affected by Polycythemia Vera as a positive control for $\mathrm{Val}(617) \mathrm{Phe}$ mutation, were extracted using standard procedures. The PCR fragments of JAK2 exon 12 were amplified using the following oligonucleotide primers: JAK2-F (5' TTCCTGTACCACTCTT GCTC 3'), JAK2-R (5' TTTCAGGATCACAGCTAGGT 3'). PCRs were performed in a volume of $25 \mu 1$, containing $100 \mathrm{ng}$ genomic DNA, 6 pmol forward and reverse primers, $200 \mu \mathrm{M}$ 
dNTP, 0.3 U Expand High Fidelity Plus Taq (Roche Diagnostics, Monza) and buffer $2\left(1.75 \mathrm{mM} \mathrm{MgCl}_{2}\right)$. PCRs were initiated by a denaturation step at $94^{\circ} \mathrm{C}$ for $5 \mathrm{~min}$, followed by 33 cycles at $94^{\circ} \mathrm{C}$ for $45 \mathrm{sec}, 58^{\circ} \mathrm{C}$ for $30 \mathrm{sec}$, and $72^{\circ} \mathrm{C}$ for $45 \mathrm{sec}$; a final extension was performed at $72^{\circ} \mathrm{C}$ for $5 \mathrm{~min}$. The 12th coding exon with flanking intron sequences of the JAK2 gene was screened for Val(617)Phe mutation by dHPLC (Wave ${ }^{\mathrm{TM}}$ System, MD Transgenomic Inc., Omaha, Nebraska, USA). The PCR products were denatured at $95^{\circ} \mathrm{C}$ for $5 \mathrm{~min}$ and cooled down a temperature ramp of $1^{\circ} \mathrm{C} / \mathrm{min}$ to $65^{\circ} \mathrm{C}$; the last step consisted of $1 \mathrm{~min}$ at $65^{\circ} \mathrm{C}$. The samples were kept cool until $10 \mu 1$ were automatically inserted into a preheated reversed phase column based on non-porous (polystyrene-divinylbenzene) particles (DNA-Sep, Transgenomic, San Jose, USA). DNA was eluted on a linear acetonitrile gradient consisting of buffer A (0.1 M triethylammonium acetate; TEAA)/buffer B (0.1 M TEAA, $25 \%$ acetonitrile). Gradient elution and melting temperature conditions were determined using WaveMaker Navigator ${ }^{\mathrm{TM}}$ version 1.5.4 software (Transgenomic). On the basis of the PCR product (419 bp) the nucleotide sequence analysis programme calculated the melting temperature of the domains contained in the sequences of interest at $54.2^{\circ} \mathrm{C}$. The electropherograms from GL15 were compared with the normal sequenced controls and with the electropherogram generated from the Polycythemia Vera affected patient.

\section{Results}

It is possible that different glioblastoma cell lines could retain some biochemical regulatory pathways typical of different glial precursors. The GL15 glioblastoma derived human cell line has been shown to be tumorigenic in vivo with the same proliferative and invasive properties of glioblastoma (23). In this cell line the high expression of vimentin, an embryonic intermediate filament protein, was previously shown $(12,13)$. In order to further characterize this cell line, we analysed the expression of nestin. Our results show a high expression of nestin in GL15 cells, both in the absence and in the presence of serum in the culture medium (Fig. 1A). The high expression of the embryonic intermediate filament proteins, vimentin and nestin, is considered a characteristic of astrocyte restricted precursors (16).

Due to the fact that the expression of JAK2 is developmentally regulated and that this protein tyrosine kinase is undetectable in the normal adult brain, we analysed the presence of the active form of JAK2 in GL15 cells as a possible target for specific pharmacological approaches.

In analogy with some leukaemia cells, the active form of JAK2 is present in GL15 cells also in the absence of exogenous growth factors and cytokines: The phosphorylated form of JAK2 is present in GL15 cells after 3 days of culturing in serum starvation conditions, as evaluated by using the anti-phospho-JAK2 (Tyr1007/1008) antibody (Fig. 1B). The levels of phospho-JAK2 are not significantly affected by the serum starvation conditions, as evaluated by densitometric analysis and normalization against the $\beta$-actin content (Fig. 1B). The main explanations of this result are: i) In the absence of serum in the culture medium, autocrine and paracrine loops are generated by endogenously produced growth factors and their receptors, able to elicit cellular responses involving the activity of JAK2, ii) an altered control of JAK2 activity, deriving from the genetic abnormalities involving the JAK2 gene or from the presence of abnormally activated transduction systems.

In order to investigate if, in analogy with some leukaemia cells, genomic alterations could be the basis for the constitutive activation of JAK2, the localization of the JAK2 gene was analysed by FISH, using the clone RPI-134N20 probe. Our results show a normally localized hybridization signal on both chromosomes 9, absent on $\operatorname{del}(9)($ p22) (Fig. 1C).

Moreover, we analysed the possible occurrence of a specific mutation of the JAK2 gene, observed in patients affected by Polycytemia Vera. Screening analysis with dHPLC was used. A wild-type chromatogram, with one single peak indicative of no mutation, was obtained in the GL15 cells and in the negative control. The electropherograms from the GL15 cells were not equal to those generated from the positive control (Polycythemia Vera) (data not shown). Therefore, at this state of experimentation, abnormalities of the JAK2 gene are not directly involved in the constitutive activation of JAK2 in GL15 cells.

We evaluated the effects of $10 \mu \mathrm{M}$ tyrphostin AG490 (the inhibitor of JAK2 activity) on JAK2 autophosphorylation by using the anti-phospho-JAK2 (Tyr1007/1008) antibody. Our results show that, 3 days after treatment with AG490, the active form of JAK2 was significantly reduced (Fig. 2A).

The biological response of GL15 cells to AG490 was analysed. Our working hypothesis is that the response of at least subpopulations of GL15 cells could mimic the response of normal or mutated astrocytic precursors. In this respect it should be noted that AG490 has been shown to be ineffective on normal human astrocyte growth (24). Three days after treatment, tyrphostin AG490 significantly inhibits GL15 cell growth (Fig. 2B). Moreover, a huge morphological effect is observed by contrast phase microscopy: A pheno-type characterised by very thick and elongated processes arises (Fig. 2C).

In order to verify if these effects could result from an induction of differentiation, we analysed the expression of the glial fibrillary acidic protein (GFAP), the marker of mature astrocytes $(25,26)$, by immunocytochemistry and Western blotting. The immunocytochemistry analysis shows the same mosaic pattern of GFAP expression in GL15 cells both in the control conditions and after treatment with tyrphostin AG490 (Fig. 2D). Immunoblot analysis confirms that the level of GFAP expression is not affected (Fig. 2E). Therefore tyrphostin AG490 does not induce differentiation in GL15 cells.

When we investigated by immunocytochemistry whether an abnormal polymerization of $\beta$-tubulin, the basic component of the cytoskeleton and of the mitotic spindle, was involved in the acquired phenotype, the main results were: i) B-tubulin constitutes the scaffold for the elongated processes, and ii) mitotic figures are totally absent in the AG490-treated cells, while mitotic figures, either in metaphase or in anaphase, are evident in the control cells (Fig. 3A).

A possible explanation is a cytostatic effect: AG490 inhibits JAK2-mediated signal transduction systems, elicited 
$\mathbf{A}$

\section{Vimentin}

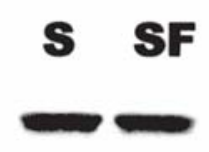

\section{$\mathbf{S} \mathbf{S F}$}

\section{Nestin}

B

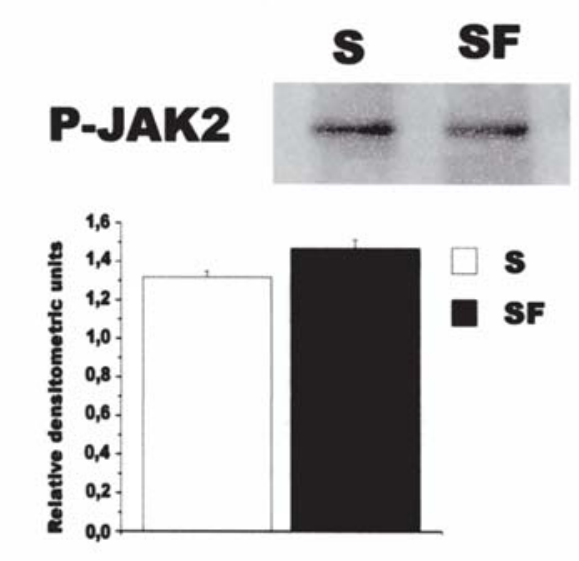

C

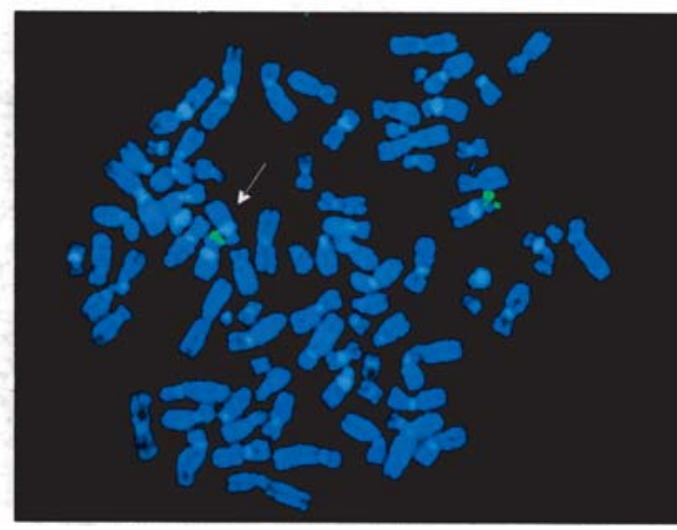

Figure 1. Vimentin and nestin expression, phospho-JAK2 levels and JAK2 gene localization in GL15 cells. (A) Immunoblot analysis of vimentin and nestin, after 3 days of subculturing in the presence (S) and in the absence (SF) of serum. (B) Immunoblot and densitometric analysis of phospho-JAK2, after 3 days of subculturing in the presence (S) and in the absence (SF) of serum. (C) FISH experiment with the clone RP1-134N20 in green which hybridizes with both normal chromosomes 9 (arrow). No green signal is present on $\operatorname{del}(9)(\mathrm{p} 22)$.

by endogenously produced growth factors and cytokines able to promote the G0/G1 transition of the cell cycle. This possibility was investigated by cell cycle analysis, performed after propidium iodide staining.

Tyrphostin AG490 deeply affects the cell cycle profile: A significant decrease of the G0/G1 phase combined with a significant increase of the $\mathrm{S}$ phase was observed (Fig. 3B). This result indicates that the main effect of AG490 is an S phase arrest which also involves a partial impairment of the $\mathrm{G} 2 / \mathrm{M}$ transition. In fact the $\mathrm{S}$ phase arrest should imply a significant reduction of the percentage of cells in the G2/M phase unless the G2/M phase was similarly affected. Due to the fact that, when inspecting the nuclear morphology by DAPI staining (data not shown) and mitotic spindles by immunocytochemistry, we did not observe any mitotic figures in the AG490-treated cells, we concluded that, the G2, and not the $\mathrm{M}$ phase, must be affected.

It should be noted that an $\mathrm{S}$ phase arrest is quite unusual if we consider that the inhibition of transduction systems downstream the activation of the growth factor and cytokine receptors has, as a main effect, a G1 phase arrest.

We can not rule out other possibilities: An abnormal and abortive stimulation of the G1/S transition, or an induction of apoptosis occurring during the $\mathrm{S}$ and the $\mathrm{G} 2$ phases of the cell cycle.

A significant increase in the percentage of cells with a sub-G0/G1 nuclear DNA content is usually observed when apoptosis occurs during the G0/G1 phase. A more complicated pattern of the nuclear DNA content can result from an induction of apoptosis in the other phases of the cell cycle: In this case the increase in the percentage of cells with a subG2/M DNA content could be misleadingly evaluated as an increase in the percentage of cells in the $S$ phase. In order to check this possibility, the induction of apoptosis by AG490 was investigated by an ELISA method aimed at quantifying the presence of cytoplasmic nucleosomes. Our results show a very low induction of apoptosis (Fig. 3C). Therefore tyrphostin AG490 actually induces an increase in the percentage of cells in the $\mathrm{S}$ phase of the cell cycle.

Our results constitute the first demonstration that, in analogy with some leukaemia cells, glioblastoma cells can display a constitutive activation of JAK2. Moreover, the unusual $\mathrm{S}$ phase arrest induced by tyrphostin AG490 can constitute a specific response of glioblastoma cells in which a combination of glial precursor characteristics and genetic alterations occurs.

\section{Discussion}

There are many reports concerning the possibility that glioma cells could originate from mutated glial precursor cells $(1,2)$. This research constitutes an important topic because some molecular mechanisms, active during glial cell development but absent in adult glia, could be involved in the pathogenesis of gliomas and, therefore, could be targets for a specific pharmacological approach. It is difficult to reproduce in vitro the complexity of cell types observed in human glioblastomas. However, the use of glioblastoma cell lines allows experimental approaches able to select specific cell populations and to study specific molecular mechanisms involved in the control of cell growth and differentiation.

Our study shows that the GL15 glioblastoma derived human cell line displays some characteristics of astrocyte restricted precursors. Moreover, in analogy with some leukaemia cells, the active form of JAK2 is present in GL15 cells, also in the absence of exogenous growth factors and 
A

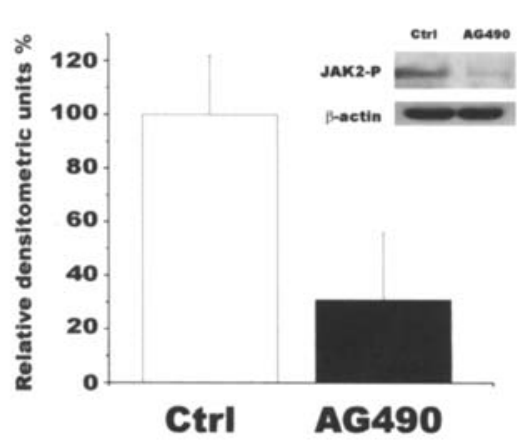

B

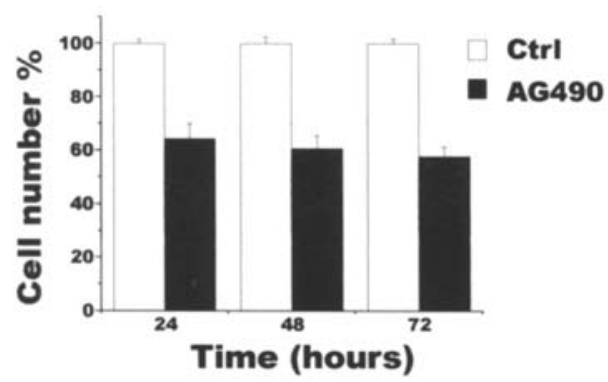

C

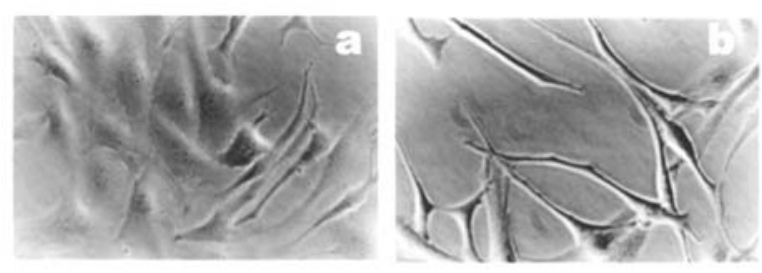

D
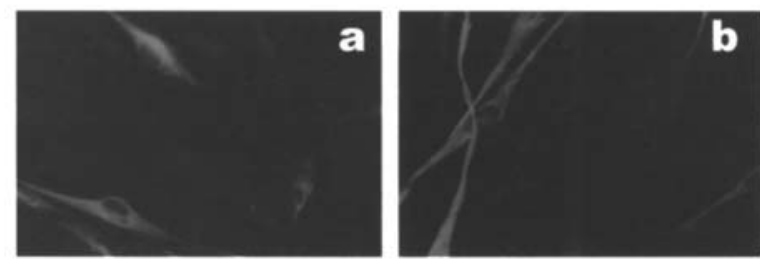

E

\section{Ctrl AG490}

Figure 2. Effects of $10 \mu \mathrm{M}$ AG490 on GL15 cells 3 days after treatment in serum-free conditions. (A) Immunoblot and densitometric analysis of the phosphorylated (Tyr1007/1008) form of JAK2. Ctrl, control; AG490, $10 \mu \mathrm{M}$ tyrphostin AG490. (B) Cell count. Ctrl, control; AG490, 10 $\mu$ M tyrphostin AG490. (C) Contrast phase microscopy. (a) Control, (b) $10 \mu \mathrm{M}$ tyrphostin AG490 (original magnification x400). (D) Immunofluorescence staining of GFAP. (a) Control, (b) $10 \mu \mathrm{M}$ tyrphostin AG490 (original magnification x400). (E) Immunoblot analysis of GFAP expression. Ctrl, control; AG490, $10 \mu \mathrm{M}$ tyrphostin AG490. ${ }^{*} \mathrm{P}<0.05,{ }^{* *} \mathrm{P}<0.001$, Student's t-test.

\section{A}
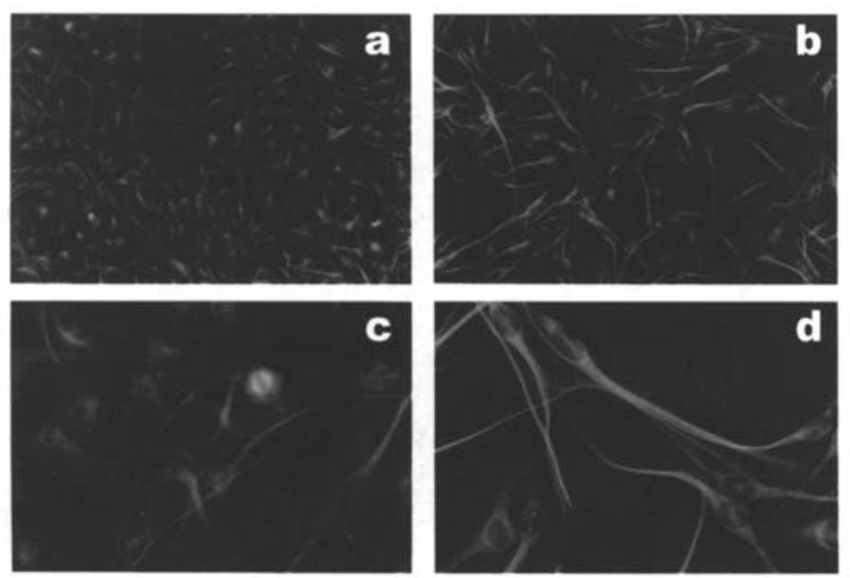

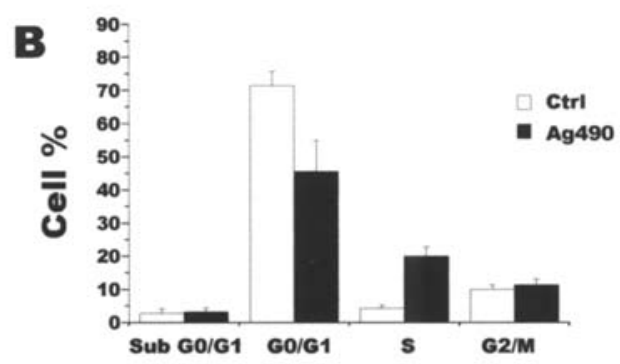

C

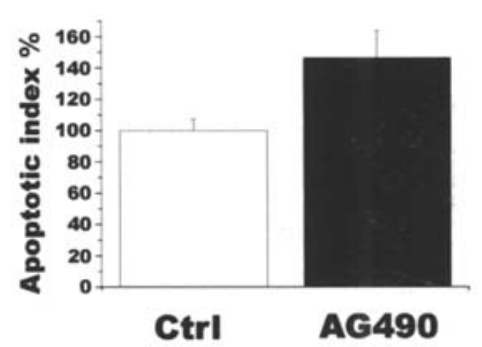

Figure 3. Effects of tyrphostin $10 \mu \mathrm{M}$ AG490 on the GL15 cell cycle, 3 days after treatment in serum-free conditions. (A) Immunofluorescence staining of ß-tubulin. (a) Control, (b) $10 \mu \mathrm{M}$ tyrphostin AG490 (original magnification x100), (c) control, (d) $10 \mu \mathrm{M}$ tyrphostin AG490 (original magnification x400). (B) Cell cycle analysis. Ctrl, control; AG490, $10 \mu \mathrm{M}$ tyrphostin AG490. (C) ELISA detection of cytoplasmic nucleosomes. Ctrl, control; AG490, 10 $\mu$ M tyrphostin AG490. 
cytokines. The expression of JAK2, evident during CNS development but undetectable in the adult brain, could be related to the precursor characteristics of GL15 cells. On the contrary, the constitutive activation of JAK2 does not depend on the chromosomal translocations affecting the JAK2 gene: We found a normal localization of the JAK2 gene. Moreover, the mutation of the JAK2 gene, observed in patients affected by Polycythemia Vera, is absent in GL15 cells. Therefore a direct involvement of the JAK2 gene abnormalities in the constitutive activation of JAK2 is ruled out. The constitutive activation of JAK2 could be a downstream effect of abnormally activated transduction systems.

The abnormally activated JAK2 could be the basis for the constitutive activation of the signal transducer and activator of transcription 3 (STAT3), observed in GL15 cells (27) and in human glioblastomas (24). This idea is supported by the fact that: i) The abnormal expression of cytokines, and their receptors, belonging to the interleukin 6 family and acting during glial cell development (28-34), has been detected in human glioblastomas: These cytokines elicit transduction systems involving the activity of JAK2 and leading to the activation of STAT3. ii) Chromosomal abnormalities, leading to the over-expression of the epidermal growth factor (EGF) receptor, are a common finding in human glioblastomas $(1,2)$ and are observed in GL15 cells: It has been recently reported that the over-expression of the EGF receptor can lead to a JAK2-mediated activation of STAT3 in primary esophageal keratinocytes (35). We have considered JAK2 as a possible target for a specific pharmacological approach.

Our results show that, in GL15 cells, the inhibition of JAK2 activity by tyrphostin AG490 induces, as its main effect, an $\mathrm{S}$ phase arrest in the cell cycle progression. This $\mathrm{S}$ phase arrest induced by AG490 constitutes an unusual cellular response, because it has been demonstrated that in several cellular systems AG490 induces a G1 phase arrest $(18,36)$. A possible target of tyrphostin AG490 is the activation of the cyclin-dependent-kinase 2 (CDK2) (37), an enzyme involved in the control of the $\mathrm{G} 1$ and $\mathrm{S}$ phase progression. In fact $30 \mu \mathrm{M}$ AG490 has been reported to inhibit the activation of CDK2 by acting on an unknown mechanism. It is possible that this or other unknown mechanisms are active in GL15 cells, and that these mechanisms are elicited by the abnormal activation of JAK2. The presence, in glioblastoma cells, of abnormal biochemical pathways, specifically inhibited by AG490, is confirmed by a report showing that 25-50 $\mu \mathrm{M}$ AG490, able to inhibit STAT3 activation and unable to affect the cell growth of normal human astrocytes, induces apoptosis in the U251 glioblastoma derived human cell line (24).

Our hypothesis is that, in GL15 cells, the activation of JAK2 becomes part of an altered biochemical background which constitutes a specific characteristic of subpopulations of glioblastoma cells. The presence of JAK2-mediated signal transduction systems (derived from the glial precursor characteristics of GL15 cells) as well as the altered activity of biochemical pathways involved in the control of cell cycle progression (derived from the neoplastic characteristics of GL15 cells) are the basis of the altered biochemical background. An abnormally activated biochemical pathway, absent in normal cells, could be the target of the specific action of tyrphostin AG490 in glioblastoma cells.

\section{Acknowledgements}

We are grateful to Dr Peter Marynen, from the Centre for Human Genetics, Leuven, Belgium for kindly providing the clone RP1-134N20 probe. We thank Dr B.J. Richards for the text revision. This study was supported by a grant from the Fondazione Cassa Risparmio Perugia.

\section{References}

1. Maher EA, Furnari FB, Bachoo RM, Rowitch DH, Louis DN, Cavenee WK and DePinho RA: Malignant glioma: genetics and biology of a grave matter. Genes Dev 15: 1311-1333, 2001.

2. Holland EC: Gliomagenesis: genetic alterations and mouse models. Nat Rev Genet 2: 120-129, 2001.

3. Rane GS and Reddy EP: Janus kinases: components of multiple signaling pathways. Oncogene 19: 5662-5679, 2000.

4. Cattaneo E, Conti L and De-Fraja C: Signalling through the JAK-STAT pathway in developing brain. Trends Neurosci 22: 365-369, 1999.

5. He F, Ge W, Martinowich K, Becker-Catania S, Coskun V, Zhu W, Wu H, Castro D, Guillemot F, Fan G, de Vellis J and Sun YE: A positive autoregolatory loop of Jak-STAT signalling controls the onset of astrogliogenesis. Nat Neurosci 8: 616-625, 2005.

6. De-Fraja C, Conti L, Magrassi L, Covoni S and Cattaneo E: Members of the JAK-STAT proteins are expressed and regulated during development in the mammalian forebrain. $\mathbf{J}$ Neurosci Res 54: 320-330, 1998

7. Arai K, Lee F, Miyajima A, Miyatake S, Arai N and Yokota T: Cytokines: coordinator of immune and inflammatory response. Annu Rev Biochem 59: 783-836, 1990.

8. Merrill JE and Benveniste EN: Cytokines in inflammatory brain lesion: helpful and harmful. Trends Neurosci 19: 331-338, 1996.

9. Natarajan C, Sriram S, Muthian G and Bright JJ: Signaling through JAK2-STAT5 pathway is essential for IL-3-induced activation of microglia. Glia 47: 188-196, 2004.

10. Swanson RA, Ying W and Kauppinen TM: Astrocyte influences on ischemic neuronal death. Curr Mol Med 4: 193-205, 2004.

11. Meydan N, Grunberger T, Dadi H, Shahar M, Arpaia E, Lapidot Z, Leeder JS, Freedman M, Cohen A, Gazit A, Levitzki A and Roifman CM: Inibition of acute lymphoblastic leukaemia by a JAK-2 inhibitor. Nature 379: 645-648, 1996.

12. Bocchini V, Beccari T, Arcuri C, Bruyere L, Fages C and Tardy M: Glial fibrillary acidic protein and its encoding mRNA exibit mosaic expression in a glioblastoma multiform cell line of clonal origin. Int J Dev Neurosci 11: 485-492, 1993.

13. Arcuri C, Bocchini V, Guerrieri P, Fages C and Tardy M: PKA and PKC activation induces opposite glial fibrillary acidic protein (GFAP) expression and morphology changes in a glioblastoma multiform cell line of clonal origin. J Neurosci Res 40: 622-631, 1995.

14. Moretto G, Brutti N, De Andelis V, Arcuri C and Bocchini V: A time-dependent increase in glial fibrillary acidic protein expression and glutammine synthetase activity in long-term subculture of the GL15 glioma cell line. Cell Mol Neurobiol 17: 509-519, 1997.

15. Castigli E, Arcuri C, Giovagnoli L, Luciani R, Giovagnoli L, Secca T, Gianfranceschi GL and Bocchini V: Interleukin-1ß induces apoptosis in GL15 glioblastoma-derived human cell line. Am J Physiol Cell Physiol 279: C2043-C2049, 2000.

16. Lee JC, Mayer-Proschel M and Rao MS: Gliogenesis in the central nervous system. Glia 30: 105-121, 2000.

17. Lacronique V, Boureux A, Valle VD, Poirel H, Quang CT, Mauchauffe M, Berthou C, Lessard M, Berger R, Ghysdael J and Bernard OA: A TEL-JAK2 fusion protein with constitutive kinase activity in human leukaemia. Science 278: 1309-1312, 1997.

18. Miyamoto N, Sugita K, Goi K, Inukai T, Lijima K, Tezuka T, Kojika S, Nakamura M, Kagami K and Nakazawa S: The JAK2 inhibitor AG490 predominantly abrogates the growth of human B-precursor leukemic cells with 11 q23 translocation or Philadelphia chromosome. Leukemia 15: 1758-1768, 2001.

19. Laemmli UK: Cleavage of structural protein during the assembly of the head of bacteriophage T4. Nature 227: 680-685, 1970 . 
20. Towbin H, Staelin T and Gordon J: Electrophoretic transfer of protein from polyacrylamide gels in nitrocellulose sheets. Procedure and some applications. Proc Natl Acad Sci USA 76: 4350-4354, 1979.

21. Tognon M, Casalone R, Martini F, De Mattei M, Granata P, Minelli E, Arcuri C, Collini P and Bocchini V: Large T antigen coding sequences of two DNA tumor viruses, BK and SV40, and nonrandom chromosome changes in two glioblastoma cell lines. Cancer Genet Cytogenet 90: 17-23, 1996.

22. Dierlamm J, Wlodarska I, Michaux R, La Starza R, Zeller W, Mecucci $\mathrm{C}$ and Van den Berghe H: Successful use of the same slide for consecutive fluorescence in situ hybridization (FISH) experiments. Genes Chromosomes Cancer 16: 261-264, 1996.

23. Guillamo JS, Lisovoski F, Christov C, Le Guerinel C, Defer GL, Peschanski $\mathrm{M}$ and Lefrancois T: Migration pathways of human glioblastoma cells xenografted into the immunosuppressed rat brain. J Neurooncol 52: 205-215, 2001.

24. Rahaman SO, Harbor PC, Chernova O, Barnett GH, Vogelbaum MA and Haque SJ: Inhibition of costitutive active Stat3 suppresses proliferation and induces apoptosis in glioblastoma multiforme cells. Oncogene 21: 8404-8413, 2002.

25. Bignami A, Eng LF, Dahl D and Uyeda CT: Localization of the glial fibrillary acidic protein in astrocytes by immunoflorescence. Brain Res 43: 429-435, 1972.

26. Eng LF: Glial fibrillary acidic protein: The major protein of glia intermediate filament in differentiated astrocytes. J Neuroimmunol 8: 203-214, 1985.

27. Paillaud E, Costa S, Fages C, Plassat JL, Rochette-Egly C, Monville $\mathrm{C}$ and Tardy M: Retinoic acid increases proliferation rate of GL15 glioma cells, involving activation of STAT-3 transcription factor. J Neurosci Res 67: 670-679, 2002.

28. Watanabe S and Arai K: Roles of the JAK-STAT system in signal transduction via cytokine receptors. Differentiation and gene regulation. Curr Opin Genet Dev 6: 587-596, 1996.
29. Bonni A, Sun Y, Nadal-Vicens M, Bhatt A, Frank DA, Rozovsky I, Stahl N, Yancopoulos GD and Greenberg ME: Regulation of gliogenesis in the central nervous system by the JAK-STAT signalling pathway. Science 278: 477-483, 1997.

30. Rajan P and McKay RD: Multiple routes to astrocytic differentiation in the CNS. J Neurosci 18: 3620-3629, 1998.

31. Tarasenko YI, Yu Y, Jordan PM, Bottenstein J and Wu P: Effect of growth factors on proliferation and phenotypic differentiation of human fetal neural stem cells. J Neurosci Res 78: 625-636, 2004.

32. Fukuda $\mathrm{S}$ and Taga T: Cell fate determination regulated by a transcriptional signal network in the developing mouse brain. Anat Sci Int 80: 12-18, 2005.

33. Adachi T, Takanaga $\mathrm{H}$, Kunimoto $\mathrm{M}$ and Asou $\mathrm{H}$ : Influence of LIF and BMP-2 on differentiation and development of glial cells in primary cultures of embryonic rat cerebral hemisphere. J Neurosci Res 79: 608-615, 2005

34. Gregg C and Weiss S: CNTF/LIF/gp130 receptor complex signalling maintains a VZ precursor differentiation gradient in the developing ventral forebrain. Development 132: 565-578, 2005.

35. Andl CL, Mizushima T, Oyama K, Bowser M, Nakagawa $\mathrm{H}$ and Rustgi AK: EGFR-induced cell migration is mediated predominantly by the JAK-STAT pathway in primary esophageal keratinocytes. Am J Physiol Gastrointest Liver Physiol 287: G1227-1237, 2004.

36. Savell J, Ma Y, Morrow KS, Jove R, Olashaw N, Moseley PL, Cress WD and Wharton W: AG490 inhibits G1-S traverse in $\mathrm{BALB} / \mathrm{c}-3 \mathrm{~T} 3$ cells following either mitogenic stimulation or exogenous expression of E2F-1. Mol Cancer Ther 3: 205-213, 2004.

37. Kleinberger-Doron N, Shelah N, Capone R, Gazit A and Levitzki A: Inhibition of Cdk2 activation by selected tyrphostins causes cell cycle arrest at late G1 and S phase. Exp Cell Res 241: 340-351, 1998. 